03,05

\title{
Воздействие импульсов эксимерного лазера на светоизлучающие InGaAs/GaAs-структуры c (Ga, Mn)As-слоем
}

\author{
(c) О.В. Вихрова ${ }^{1}$, Ю.А. Данилов ${ }^{1}$, Б.Н. Звонков ${ }^{1}$, И.Л. Калентьева ${ }^{1}$, Ю.М. Кузнецов ${ }^{1}$, \\ А.В. Нежданов ${ }^{2}$, А.Е. Парафинн, Д.В. Хомицкий ${ }^{2}$, И.Н. Антонов ${ }^{1}$
}

${ }^{1}$ Научно-исследовательский фризико-технический институт Нижегородского государственного университета им. Н.И. Лобачевского,

Нижний Новгород, Россия

${ }^{2}$ Нижегородский государственный университет им. Н.И. Лобачевского,

Нижний Новгород, Россия

${ }^{3}$ Институт фризики микроструктур РАН,

Нижний Новгород, Россия

E-mail: vikhrova@nifti.unn.ru

Поступила в Редакцию 9 октября 2020 г.

В окончательной редакции 20 ноября 2020 г.

Принята к публикации 24 ноября 2020 г.

Исследована возможность модифицирования лазерным отжигом свойств слоя (Ga, Mn)As, расположенного на поверхности квантово-размерной InGaAs/GaAs-структуры, с сохранением ее излучательных свойств. Для проведения исследований сочетанием методов МОС-гидридной эпитаксии и импульсного лазерного нанесения были изготовлены структуры с четырьмя квантовыми ямами InGaAs/GaAs, (содержание индия от 0.08 до 0.25), расположенными на различном расстоянии от слоя ( $\mathrm{Ga}, \mathrm{Mn}) \mathrm{As}$. В процессе исследований варьировалась плотность энергии излучения (от 200 до $360 \mathrm{~mJ} / \mathrm{cm}^{2}$ ) импульсного эксимерного лазера LPX-200, и по изменению спектров фотолюминесценции квантовых ям определялась глубина воздействия лазера. При описании полученных результатов была использована модель процесса лазерного отжига, основанная на решении задачи о распространении тепла в одномерной GaAs-системе с учетом слоя $(\mathrm{Ga}, \mathrm{Mn}) \mathrm{As}$ на поверхности. Анализировались изменения структурных и гальваномагнитных свойств образцов в результате лазерного воздействия. Показано, что вследствие импульсного лазерного воздействия при диапазоне плотности энергии лазерного излучения $250-300 \mathrm{~mJ} / \mathrm{cm}^{2}$ удается сохранить излучательные свойства активной области (квантовой ямы InGaAs/GaAs), расположенной на расстоянии $10-12 \mathrm{~nm}$ от слоя $(\mathrm{Ga}, \mathrm{Mn}) \mathrm{As}$ и модифицировать ферромагнитные свойства полупроводника ( $\mathrm{Ga}, \mathrm{Mn}) \mathrm{As}$, а именно: увеличить температуру фазового перехода ферромагнетик-парамагнетик до значений не менее $120 \mathrm{~K}$. Полученные результаты перспективны для развития технологии приборов спиновой оптоэлектроники.

Ключевые слова: импульсный лазерный отжиг, МОС-гидридная эпитаксия, импульсное лазерное нанесение, квантово-размерная структура, ферромагнитный полупроводник $(\mathrm{Ga}, \mathrm{Mn}) \mathrm{As}$.

DOI: 10.21883/FTT.2021.03.50585.214

\section{1. Введение}

Разбавленные магнитные полупроводники (РМП) являются интересными и привлекательными материалами для современной оптической электроники. Основная цель их использования - применение синергетических эффектов, возникающих благодаря сочетанию полупроводниковых и магнитных свойств РМП, в приборных разработках нового поколения. Разбавленный магнитный полупроводник ( $\mathrm{Ga}, \mathrm{Mn}) \mathrm{As}$ является наиболее исследованным из соединений $\mathrm{A}^{3} \mathrm{~B}^{5}$, легированных примесями переходных металлов, к тому же для него характерна хорошая технологическая совместимость с полупроводниковыми гетеронаноструктурами на основе GaAs. Bместе с тем, имеющиеся на сегодняшний день ограничения по его применению для разработки оптоэлектронных элементов обусловлены дорогостоящей технологией его получения (как правило, это низкотемпературная молекулярно-лучевая эпитаксия (МЛЭ)) и недостаточно высокой температурой Кюри (температурой сохранения ферромагнитных свойств). Кроме того, если рассматривать использование (Ga, Mn)As в сочетании с квантово-размерными светоизлучающими структурами (для формирования, например, источников циркулярно-поляризованного излучения - спиновых светоизлучающих диодов), то здесь исследования в основном выполнены с использованием технологии МЛЭ для изготовления приборных структур [1-4].

Ранее нами было показано, что для получения ферромагнитных полупроводниковых слоев ( $\mathrm{Ga}, \mathrm{Mn}) \mathrm{As}$ может быть использовано импульсное лазерное нанесение (ИЛН) [5,6]. Этот метод был успешно применен для получения в едином ростовом цикле с МОС-гидридной эпитаксией (МОСГЭ) при атмосферном давлении светоизлучающих гететеронаноструктур InGaAs/GaAs (диоды Зенера и $p-i-n$-диоды), демонстрирующих циркулярнополяризованное излучение $[7,8]$. Также было показано, что применение импульсного лазерного отжига слоев 
( $\mathrm{Ga}, \mathrm{Mn}) \mathrm{As}$, сформированных методом ИЛН, позволило существенным образом повысить температуру Кюри (от 30-40 до 80-100 K) [9]. Использование воздействия импульсного эксимерного лазера способствовало существенному увеличению температуры (от 30 до $110 \mathrm{~K}$ ) наблюдения циркулярно-поляризованного электролюминесцентного излучения туннельного спинового светоизлучающего диода InGaAs/n+ ${ }^{+}-\mathrm{GaAs} /(\mathrm{Ga}, \mathrm{Mn}) \mathrm{As}[10]$. Применяемая конструкция туннельного диода предполагает, что активная область светодиода (квантовая яма InGaAs/GaAs) расположена в глубине структуры на расстоянии около $120 \mathrm{~nm}$ от слоя $(\mathrm{Ga}, \mathrm{Mn}) \mathrm{As}$, который подвергался импульсному лазерному отжигу. Этот факт исключал значительное тепловое воздействие на квантовую яму.

Настоящая работа посвящена исследованию возможности модифицирования лазерным отжигом свойств слоя $(\mathrm{Ga}, \mathrm{Mn}) \mathrm{As}$, расположенного на поверхности квантово-размерной структуры, с сохранением ее излучательных свойств. Особенностью исследованных структур является близкое расположение (от $\sim 10 \mathrm{~nm}$ ) напряженных квантовых ям к подвергавшемуся импульсному лазерному воздействию слою $(\mathrm{Ga}, \mathrm{Mn}) \mathrm{As}$. Механические напряжения в системе $\operatorname{In}_{x} \mathrm{Ga}_{1-x} \mathrm{As} / \mathrm{GaAs}$ возникают из-за различия в параметрах кристаллической решетки этих полупроводников и приводят к „подстраиванию“ параметра решетки $\operatorname{In}_{x} \mathrm{Ga}_{1-x}$ As к арсениду галлия в латеральной плоскости и, соответственно, к увеличению его в направлении по нормали к плоскости слоя. Напряженное состояние (отсутствие пластической деформации и дислокаций несоответствия) квантовой ямы $\operatorname{In}_{x} \mathrm{Ga}_{1-x} \mathrm{As}$ сохраняется до некоторой критической толщины, зависящей от величины $x$ (в нашем случае $d_{\mathrm{InGaAs}}=10 \mathrm{~nm}-$ это условие заведомо выполняется).

Для проведения исследований сочетанием методов МОСГЭ и ИЛН были изготовлены структуры, содержащие четыре квантовые ямы InGaAs/GaAs, отличающиеся содержанием индия и расположенные на различном расстоянии от слоя $(\mathrm{Ga}, \mathrm{Mn}) \mathrm{As}$. В процессе исследований варьировалась плотность энергии лазерного облучения, и по изменению спектров фотолюминесценции квантовых ям можно было определить глубину воздействия лазерного отжига. Для описания полученных результатов была использована модель процесса лазерного отжига, представляющая собой решение задачи о распространении тепла в одномерной системе на основе GaAs c учетом присутствия слоя $(\mathrm{Ga}, \mathrm{Mn}) \mathrm{As}$ на поверхности. Кроме того, анализировались изменения структурных и гальваномагнитных свойств образцов в результате лазерного воздействия.

\section{2. Методика эксперимента}

Для исследования изменения глубины воздействия импульса эксимерного лазера на GaAs-структуры при варьировании энергии в отжигающем пучке были изготовлены тестовые структуры с квантовыми ямами

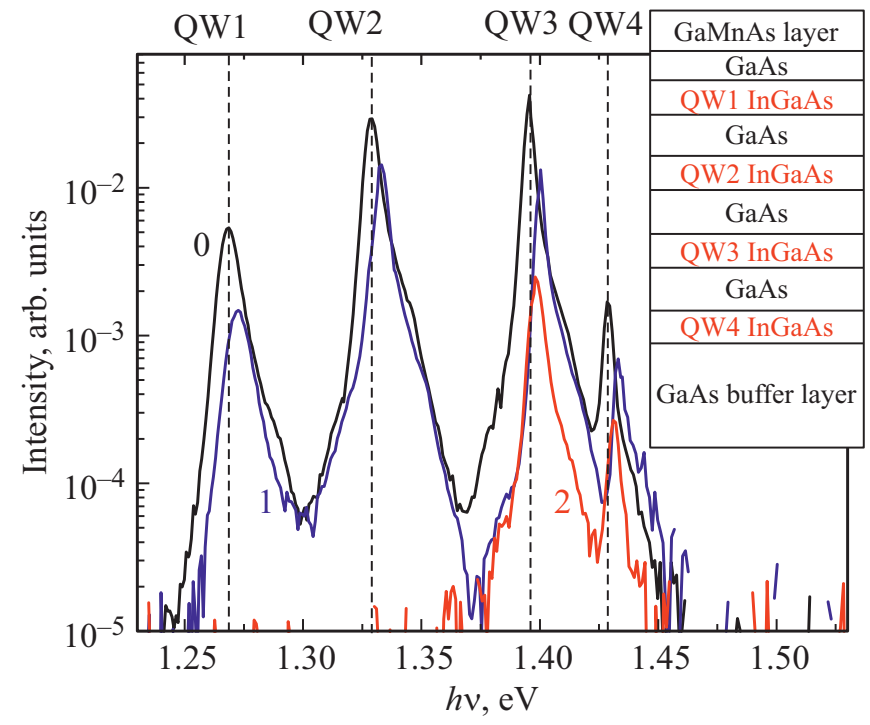

Рис. 1. Спектры фотолюминесценции структур с четырьмя квантовыми ямами с различным содержанием индия и слоем (Ga, Mn)As на поверхности: 0 - исходный образец; 1 плотность энергии в импульсе $300 \mathrm{~mJ} / \mathrm{cm}^{2} ; 2$ - плотность энергии в импульсе $360 \mathrm{~mJ} / \mathrm{cm}^{2}$. Температура измерений $77 \mathrm{~K}$. На вставке показана схема поперечного сечения структуры.

InGaAs/GaAs различного состава. Гетероструктуры изготавливались сочетанием методов МОС-гидридной эпитаксии и импульсного лазерного нанесения. Подложки представляли собой пластины полуизолирующего GaAs (100). Вначале при температуре $650^{\circ} \mathrm{C}$ формировался буферный слой GaAs толщиной $0.3-0.4 \mu \mathrm{m}$, затем при температуре $600^{\circ} \mathrm{C}$ выращивались последовательно четыре квантовые ямы $(\mathrm{QW}) \mathrm{InGaAs} / \mathrm{GaAs}$ (толщина слоя $\mathrm{In}_{x} \mathrm{Ga}_{1-x} \mathrm{As} \sim 10 \mathrm{~nm}$, толщина барьера GaAs $50 \mathrm{~nm})$, содержание индия $(x)$ увеличивалось от 0.08 до 0.25 . Для ближайшей к поверхности квантовой ямы QW1 значение $x$ составляло 0.25 , для второй от поверхности $\mathrm{QW} 2-x \approx 0.18$, далее третьей и четвертой квантовым ямам QW3 и QW4 соответствовали величины $x \approx 0.11$ и $x \approx 0.08$. Процесс МОСГЭ заканчивался формированием слоя GaAs толщиной $\sim 10 \mathrm{~nm}$. Затем температура понижалась до $330^{\circ} \mathrm{C}$, и методом импульсного лазерного нанесения формировался слой $(\mathrm{Ga}, \mathrm{Mn}) \mathrm{As}$ толщиной около $40-50 \mathrm{~nm}$. Соотношение времен распыления мишеней $\mathrm{Mn}$ и GaAs $t_{\mathrm{Mn}} / t_{\mathrm{GaAs}}$ составляло 0.15 , а содержание марганца оценивалось величиной $Y_{\mathrm{Mn}}=t_{\mathrm{Mn}} /\left(t_{\mathrm{GaAs}}+t_{\mathrm{Mn}}\right)=0.13$. Схематическое изображение структур показано на вставке к рис. 1.

Образцы изготовленных структур подвергались воздействию расфокусированного пучка излучения импульсного эксимерного лазера LPX-200 (рабочая смесь $\mathrm{KrF}$, длина волны $248 \mathrm{~nm}$, длительность импульса $\approx 30 \mathrm{~ns}$ ). При этом плотность энергии варьировалась в диапазоне от 200 до $360 \mathrm{~mJ} / \mathrm{cm}^{2}$.

Излучательные свойства исходных и отожженных лазером образцов исследовались методом измерения 
Таблица 1. Результаты анализа спектров КРС исходной и отожженных лазером структур с использованием аппроксимации их лоренцианами; приведены частоты, отвечающие положению LO-моды, TO-моды и связанной фонон-плазмонной моды (CPLP) для различных плотностей энергии импульсного лазерного воздействия

\begin{tabular}{c|c|c|c|c|c}
\hline$P, \mathrm{~mJ} / \mathrm{cm}^{2}$ & 0 & 200 & 250 & 300 & 360 \\
\hline$\omega_{\mathrm{TO}}, \mathrm{cm}^{-1}$ & $266.7 \pm 0.7$ & $264.0 \pm 0.7$ & $263.1 \pm 0.7$ & $263.2 \pm 0.7$ & $262.9 \pm 0.7$ \\
$\omega_{\mathrm{LO}}, \mathrm{cm}^{-1}$ & $288.0 \pm 0.7$ & $287.4 \pm 0.7$ & $286.1 \pm 0.7$ & $281.2 \pm 0.7$ & $280.6 \pm 0.7$ \\
$\omega_{\text {CPLP }}, \mathrm{cm}^{-1}$ & $270.0 \pm 0.7$ & $266.2 \pm 0.7$ & $265.9 \pm 0.7$ & $261.2 \pm 0.7$ & $261.0 \pm 0.7$
\end{tabular}

спектров фотолюминесценции при $77 \mathrm{~K}$. Для возбуждения фотолюминесценции использовался Не-Ne-лазер с длиной волны $632 \mathrm{~nm}$ мощностью $30 \mathrm{~mW}$.

Морфология поверхности образцов изучена методом атомно-силовой микроскопии (АСM) в атмосферных условиях с использованием сканирующей головки Smena на базе зондовой нанолаборатории NTEGRA Spectra компании NT-MDT (Зеленоград, Россия) в полуконтактном режиме с использованием зондов марки HA_NC. Шероховатость поверхности оценивалась стандартными программными методами с использованием программного обеспечения Gwyddion [11].

Спектры комбинационного рассеяния света (КРС) исследованы на комплексе NTEGRA Spectra производства NT-MDT с применением лазера с длиной волны $473 \mathrm{~nm}$. Излучение фокусировалось объективом $100 \times$ с апертурой $\mathrm{NA}=0.9$. Мощность лазерного излучения, измеренная с помощью кремниевого фотодетектора 11PD100-Si (Standa Ltd), составляла $0.5 \mathrm{~mW}$. Исследование спектров КРС проводились в геометрии обратного рассеяния. Спектроскопия КРС осуществлялась в диапазоне 50-900 $\mathrm{cm}^{-1}$ с разрешением $0.7 \mathrm{~cm}^{-1}$. Все спектры были получены при комнатной температуре. Время экспозиции составляло $120 \mathrm{~s}$.

Спектральные зависимости коэффициента отражения исследованы при комнатной температуре с помощью спектрофотометра Varian Cary 6000i в диапазоне энергий квантов света $1.5-6.0 \mathrm{eV}$ с использованием приставки отражения под углом $12.5^{\circ}$.

Исследования гальваномагнитных свойств структур проводились с использованием источника-измерителя Keithley 2400 и гелиевого криостата замкнутого цикла Janis CCS-300S/202 при температурах 10-300 K в диапазоне магнитных полей \pm 3600 Ое. При комнатной температуре сопротивление Холла и магнетосопротивление изучались в магнитных полях, достигающих значений \pm 28000 Ое $(2.8 \mathrm{~T})$.

\section{3. Результаты экспериментов}

Результаты исследований излучательных свойств исходного и отожженных лазером образцов гетеронаноструктуры со слоем ( $\mathrm{Ga}, \mathrm{Mn}) \mathrm{As}$ на поверхности представлены на рис. 1. Спектр фотолюминесценции исходного образца содержит четыре пика в области энергий кванта $1.270,1.330,1.400$ и $1.430 \mathrm{eV}$, отвечающих основным излучательным переходам в квантовых ямах QW1, QW2, QW3 и QW4 соответственно. Обнаружено, что в случае воздействия лазерного излучения с плотностью энергии в импульсе от 200 до $300 \mathrm{~mJ} / \mathrm{cm}^{2}$ интенсивность излучения всех квантовых ям уменьшается. Интенсивность ближайшей к поверхности квантовой ямы QW1 становится меньше в 4.5-5 раз, для всех остальных квантовых ям сигнал ФЛ падает примерно в 3 раза. При этом значительного уширения и смещения пиков не наблюдается. С увеличением плотности энергии в импульсе до величины $\approx 360 \mathrm{~mJ} / \mathrm{cm}^{2}$ регистрируется практически полное гашение излучения ФЛ квантовых ям QW1 и QW2 и наблюдается значительное (более чем на порядок величины) уменьшение интенсивности фотолюминесценции для квантовых ям QW3 и QW4.

Исследование поверхности исходных и отожженных эксимерным лазером образцов структур методом атомно-силовой микроскопии выявило некоторое увеличение шероховатости поверхности в результате лазерного отжига: для исходной структуры среднеквадратичная шероховатость $\left(S_{q}\right)$ слоя (Ga, Mn)As составила $5.6 \mathrm{~nm}$, а после отжига импульсом с плотностью энергии $360 \mathrm{~mJ} / \mathrm{cm}^{2} \approx 6 \mathrm{~nm}$.

Результаты исследований спектроскопии КРС для исходного и отожженных лазером образцов структуры со слоем (Ga, Mn)As на поверхности представлены на рис. 2 и в табл. 1. Спектроскопия КРС проводилась в геометрии обратного рассеяния при выполнении правил отбора, запрещающих появление в спектре ТО-моды, и в случае структуры со слоем GaAs на поверхности спектры КРС содержали интенсивный узкий пик в области LO-моды $\left(291.2 \mathrm{~cm}^{-1}\right)$ и слабо выраженный пик для ТО-моды $\left(267.4 \mathrm{~cm}^{-1}\right)$ [12]. Однако спектр исходного образца структуры с покровным слоем (Ga, $\mathrm{Mn}) \mathrm{As}$ содержит два широких пика в области LO-моды и TO-моды монокристаллического GaAs, причем пик в области частоты поперечных оптических фононов выглядит значительно интенсивнее пика вблизи частоты продольных оптических фононов (рис. 2,a). Присутствие ТО-моды может быть связано с разупорядочением в слое $(\mathrm{Ga}, \mathrm{Mn}) \mathrm{As}$ из-за сильного легирования марганцем, а также с небольшими нарушениями геометрии обратного рассеяния света и(или) отклонением ориентации пластины от плоскости (100). 

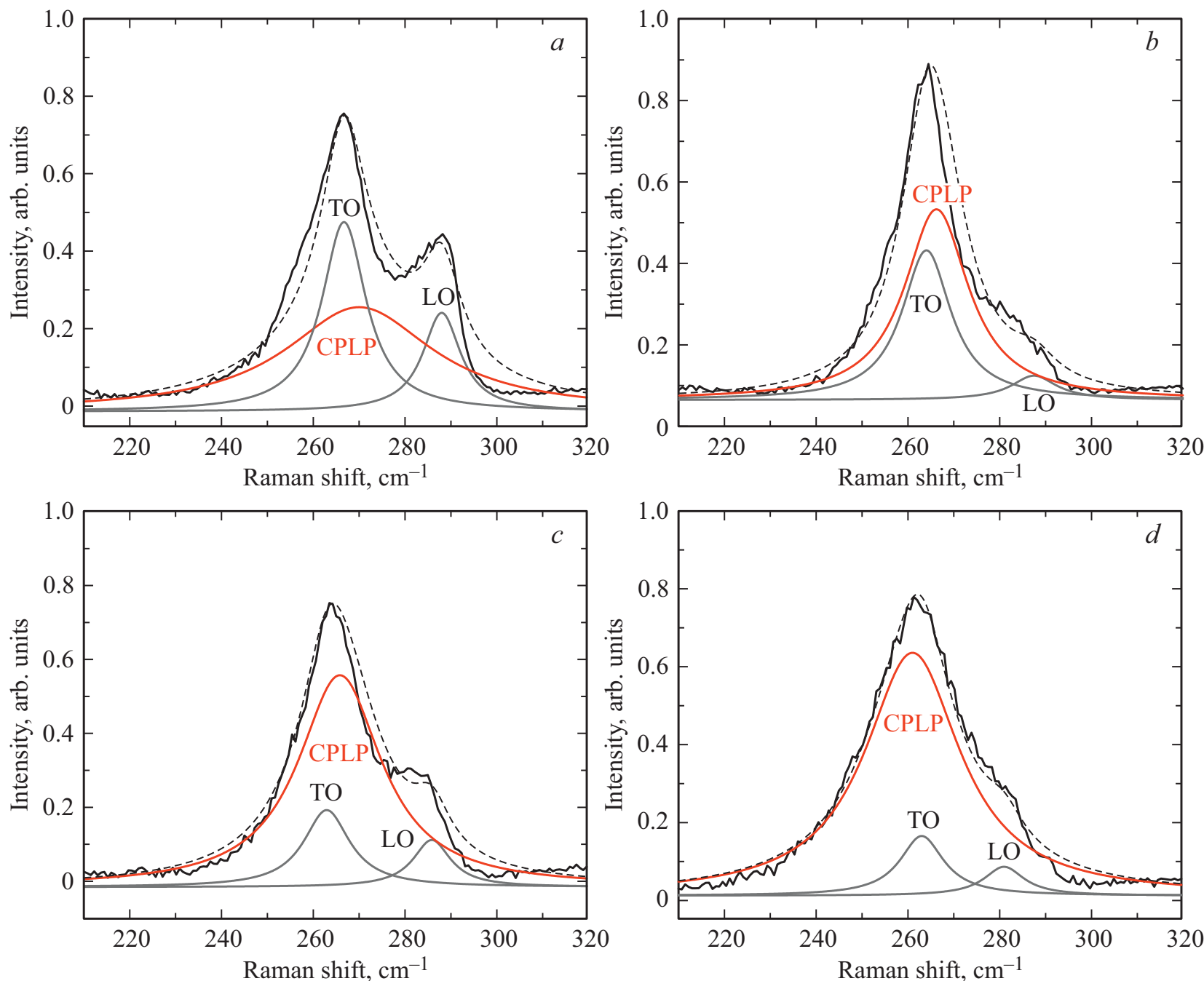

Рис. 2. Спектры комбинационного рассеяния исходной и отожженных лазером структур при $300 \mathrm{~K}: a-$ исходный образец; $b$ - образец, отожженный при плотности энергии лазерного излучения $200 \mathrm{~mJ} / \mathrm{cm}^{2} ; c$ - при плотности энергии $250 \mathrm{~mJ} / \mathrm{cm}^{2}$; $d$ - при плотности энергии $300 \mathrm{~mJ} / \mathrm{cm}^{2}$. Анализ спектров с использованием аппроксимации их лоренцианами показал, что спектры всех образцов содержат пики в области LO-моды и TO-моды GaAs и связанную фонон-плазмонную моду (CPLP).

Спектры исходного и отожженных лазером образцов значительным образом отличаются. В спектрах КРС образцов, подвергнутых импульсному лазерному воздействию, практически не виден пик, отвечающий LO-моде $\mathrm{GaAs}$. Анализ спектров КРС с использованием аппроксимации их лоренцианами показал, что спектры всех образцов содержат слабо выраженные пики в области LO-моды и TO-моды GaAs и связанную фонон-плазмонную моду (CPLP). Из-за присутствия большой концентрации марганца в поверхностном слое LO-фононная линия уширяется и смещается в сторону ТО-фонона. Подобное поведение обусловлено главным образом ослаблением связей и отклонениями от трансляционной симметрии, т.е. эффектами, неизбежно возникающими при формировании твердого раствора (Ga, Mn)As $[13,14]$. В результате волновой вектор не строго сохраняется при рассеянии, и это приводит к изменению положения фононных мод в спектрах.
Причиной появления CPLP являются сильнозатухающие продольные колебания плазмонов, которые взаимодействуют с LO-фононами через их макроскопические электрические поля. Из представленных на рис. 2 и в табл. 1 данных видно, что с увеличением плотности энергии импульсного лазерного воздействия наблюдается смещение в область меньших частот и уширение пиков LO- и ТO-мод. Интенсивность фонон-плазмонной моды при этом значительно возрастает, а положение ее также становится более низкочастотным по отношению к случаю исходного, не подвергавшегося лазерному воздействию, образца. Наблюдаемые вследствие лазерного отжига изменения спектров комбинационного рассеяния свидетельствуют о значительном повышении концентрации носителей заряда в слое $(\mathrm{Ga}, \mathrm{Mn}) \mathrm{As}$ при увеличении плотности энергии в импульсе.

Поскольку постоянная Холла $\left(R_{0}\right)$ для высоких значений концентрации носителей мала, то для корректного 
Таблица 2. Электрические параметры (слоевое сопротивление $R_{s}$ и слоевая концентрация $p_{s}$ ) исходного и отожженных лазером образцов структуры, полученные из измерений эффекта Холла при комнатной температуре. Объемная концентрация дырок $(p)$ оценивалась для толщины слоя ( $\mathrm{Ga}, \mathrm{Mn}) \mathrm{As} 45 \mathrm{~nm}$

\begin{tabular}{c|c|c|c|c}
\hline$P, \mathrm{~mJ} / \mathrm{cm}^{2}$ & 0 & 200 & 250 & 300 \\
\hline$R_{s}, \Omega / \mathrm{sq}$ & 3860 & 1280 & 1520 & 620 \\
$p_{s}, \mathrm{~cm}^{-2}$ & $7.3 \cdot 10^{14}$ & $1.54 \cdot 10^{15}$ & $1 \cdot 10^{15}$ & $3.1 \cdot 10^{15}$ \\
$p, \mathrm{~cm}^{-3}$ & $1.62 \cdot 10^{20}$ & $3.42 \cdot 10^{20}$ & $2.2 \cdot 10^{20}$ & $6.89 \cdot 10^{20}$
\end{tabular}

определения типа проводимости и значений $R_{0}$ измерения эффекта Холла при комнатной температуре выполнялись в магнитном поле до 2.8 Т. Тип проводимости в исходном и лазером отожженных слоях всегда был дырочным. Были определены слоевое сопротивление, слоевая концентрация носителей заряда (дырок) и их подвижность. Результаты представлены в табл. 2.

Видно, что в результате лазерного отжига значительно понижается слоевое сопротивление образцов более чем в 6 раз для плотности энергии $300 \mathrm{~mJ} / \mathrm{cm}^{2}$. После лазерного воздействия с плотностью энергии $200 \mathrm{~mJ} / \mathrm{cm}^{2}$ существенным образом (более чем в 2 раза) по отношению к исходному образцу возрастает слоевая концентрация дырок, при дальнейшем увеличении плотности энергии до $300 \mathrm{~mJ} / \mathrm{cm}^{2}$ концентрация возрастает более чем в 4 раза. Подвижность носителей заряда при этом остается низкой и составляет от 2 до $4 \mathrm{~cm}^{2} / \mathrm{V} \cdot \mathrm{s}$. В случае образца, облученного с плотностью энергии лазерного излучения $250 \mathrm{~mJ} / \mathrm{cm}^{2}$, наблюдается некоторое увеличение сопротивления и уменьшение слоевой концентрации дырок по отношению к образцу, облученному с $P=200 \mathrm{~mJ} / \mathrm{cm}^{2}$. Причина подобного поведения пока не ясна и требует дополнительного исследования.

\section{4. Моделирование процесса лазерного отжига структур со слоем (Ga, Mn)As на поверхности}

Моделирование процесса импульсного лазерного отжига представляло собой решение задачи о распространении тепла в одномерной системе на основе GaAs и подробно рассмотрено нами в работе [12]. В частности, было установлено, что основной вклад в эффекты, наблюдаемые в результате лазерного отжига арсенидгаллиевых гетеронаноструктур (в первую очередь, в спектрах фотолюминесценции), вносят тепловые воздействия. В рамках предложенной модели было рассчитано распределение температуры по глубине структур в различные моменты времени.

Здесь остановимся только на особенностях применения модели для структур со слоем ( $\mathrm{Ga}, \mathrm{Mn}) \mathrm{As}$. Как отмечалось ранее, тепловое воздействие происходит от поглощения полупроводником лазерного импульса $f(x, t)$, падающего на левый край образца (поверхность $(\mathrm{Ga}, \mathrm{Mn}) \mathrm{As})(x=0)$ и эффективно поглощаемого до глубины $l$ по закону $\exp (-x / l)$. Параметр $l=1 / \alpha$, где $\alpha-$ коэффициент поглощения на длине волны излучения лазера (для эксимерного $\mathrm{KrF}$-лазера $\lambda=248 \mathrm{~nm}$ ). Для GaAs величина $l$ оценивается по разным источникам $[15,16]$ в 5-10 $\mathrm{nm}$. Очевидно, что в случае $(\mathrm{Ga}, \mathrm{Mn}) \mathrm{As}$ коэффициент поглощения должен возрастать, и глубина проникновения излучения еще более уменьшается. Тем не менее, при расчетах были использованы данные из [16] с $l=10 \mathrm{~nm}$, поскольку на конечный результат эти изменения влияют мало.

Зависимость от времени интенсивности лазерного импульса имеет гауссов профиль с характерной полушириной $\Delta t=15 \mathrm{~ns}$. Моделирование распространения тепла начинается с момента, предшествующего максимуму импульса на величину $2 \Delta t=30 \mathrm{~ns}$. Еще через $15 \mathrm{~ns}$ импульс эффективно заканчивается. После этого задача моделируется в течение $55 \mathrm{~ns}$, так что общее время моделирования составляет 100 ns. Результаты показывают, что максимальный нагрев достигается почти сразу после прохождения максимума импульса, и в дальнейшем с течением времени температура снижается вследствие распространения тепла вглубь структуры и теплопередачи вовне от края $x=0$, поэтому такой промежуток времени представляется достаточным.

Падающий на поверхность поток излучения должен быть умножен на величину $(1-R)$, чтобы получить интенсивность излучения, входящего в полупроводниковую среду [17]. Здесь $R-$ коэффициент отражения на границе полупроводника с воздухом. Остановимся на выборе коэффициента отражения для слоя ( $\mathrm{Ga}, \mathrm{Mn}) \mathrm{As}$. В связи с этим, обратим внимание на полученные нами спектральные зависимости коэффициентов отражения для нелегированного GaAs и GaAs, легированного марганцем (рис. 3). Толщина исследуемых слоев (Ga, Mn)As в этом эксперименте варьировалась от 5 до $50 \mathrm{~nm}$. Пунктирная вертикальная линия на рисунке соответствует энергии кванта излучения $\mathrm{KrF}$ эксимерного лазера $(5 \mathrm{eV})$. Из представленных данных видно, что коэффициент отражения в области лазерного излучения значительным образом уменьшается с увеличением толщины слоя (Ga, Mn)As от значения около 0.7 при толщине $5 \mathrm{~nm}$ до значения 0.3 при $50 \mathrm{~nm}$. Мы полагаем, что наблюдаемое уменьшение коэффициента отражения обусловлено в значительной степени возрастанием шероховатости поверхности с увеличением толщины слоя (Ga, Mn)As. Как отмечалось выше, согласно исследованиям АСМ среднеквадратичная шероховатость слоя (Ga, Mn)As толщиной 40-50 nm составила $5.6 \mathrm{~nm}$. Эта величина значительно превышает $S_{q}$ для слоя $\mathrm{GaAs}-0.9 \mathrm{~nm}$. Здесь следует отметить, что о значительном влиянии качества обработки поверхности монокристаллических пластин GaAs на регистрируемые оптические свойства и, в первую очередь, коэффициент 


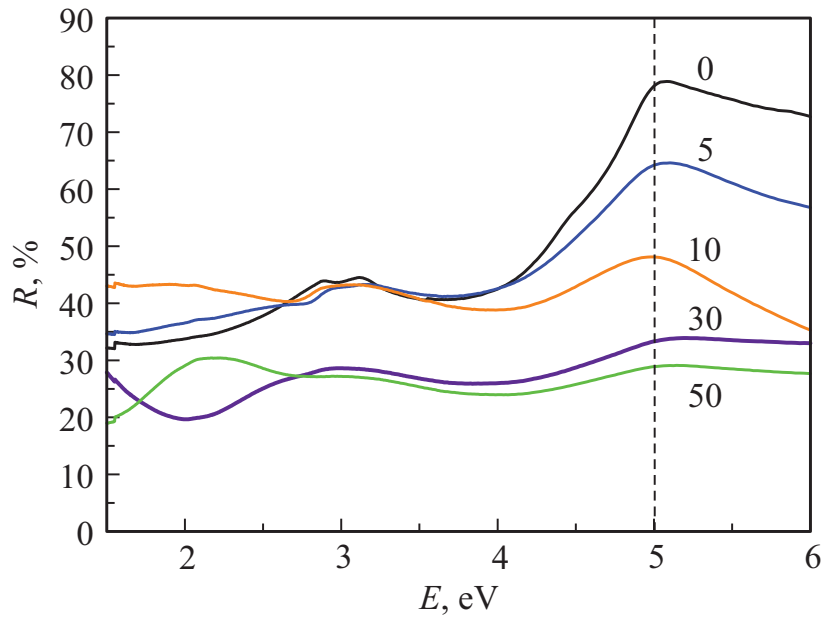

Рис. 3. Спектральные зависимости коэффициента отражения нелегированного GaAs (кривая 0) и структур со слоем $(\mathrm{Ga}, \mathrm{Mn}) \mathrm{As}$ толщиной $5,10,30$ и $50 \mathrm{~nm}$. Слой $(\mathrm{Ga}, \mathrm{Mn}) \mathrm{As}$ выращивался методом импульсного лазерного нанесения при $330^{\circ} \mathrm{C}$, содержание марганца $Y_{\mathrm{Mn}}=0.13$. Цифры около кривых означают толщину слоя в $\mathrm{nm}$. Вертикальная линия $(5 \mathrm{eV})$ соответствует энергии кванта излучения $\mathrm{KrF}$ эксимерного лазера.

отражения сообщалось в [15]. Сравнение спектральных зависимостей $R$ показало, что с возрастанием степени шероховатости поверхности GaAs коэффициент отражения уменьшается во всем диапазоне от 1.5 до $6.5 \mathrm{eV}$.

Далее необходимо учесть, что при измерении спектров отражения на использованной установке регистрируется только сигнал, попавший в детектор. Поэтому в случае шероховатой поверхности слоя (Ga, Mn) As значительная часть отраженного сигнала рассеивается и не попадает в детектор. Следовательно, при расчетах поток излучения должен быть умножен на коэффициент $(1-R-S)$, где $S-$ это доля рассеянного излучения. Если допустить, что в силу шероховатости поверхности рассеивается примерно такая же или чуть большая доля излучения, что отражается в детектор, и принять $S=0.4$, то получим, что внутрь структуры проникает мощность с коэффициентом $T=1-0.3-0.4=0.3$. Данное допущение основано на сравнении экспериментальных спектральных зависимостей коэффициентов отражения структур со слоем GaMnAs на поверхности, полученных с использованием „Плоского“ и сферического детекторов. В последнем случае обеспечивается наиболее полная регистрация отраженного излучения. Таким образом, вглубь образца проникает излучения приблизительно на 20 процентов больше, чем для образца со структурно совершенным слоем GaAs на поверхности, для которой $R=0.75$ и $T=1-R=0.25$.

В рассматриваемой системе, где перепады температур столь значительны, что коэффициент теплопроводности зависит от температуры, распространение тепла может описываться квазилинейным уравнением теплопроводности для распределения температуры $u=u(x, t)[18]$ :

$$
c(u) \frac{\partial u}{\partial t}=\frac{\partial}{\partial x}\left(k(u) \frac{\partial u}{\partial x}\right)+f(x, t) .
$$

Источник тепла в виде лазерного импульса описывается выражением

$$
f(x, t)=f_{0} \exp \left(-\frac{x}{l}\right) \frac{1}{\sqrt{2 \pi \Delta_{t}^{2}}} \exp \left(-\frac{\left(t-t_{0}\right)^{2}}{2 \Delta_{t}^{2}}\right),
$$

где выбранный начальный момент времени, отстоящий от максимума импульса на $t_{0}=2 \Delta t$, и величина дисперсии $\Delta_{t}^{2}=(\Delta t)^{2}$ определяются полушириной профиля импульса по времени.

В уравнении (1) как коэффициент теплопроводности $k(u)$, так и теплоемкость $c(u)$ являются функциями температуры. Данные для этих температурных зависимостей, представленные в [16], были аппроксимированы выражениями вида

$$
k(u)=\frac{k\left(u_{0}\right)}{1+\gamma\left(u-u_{0}\right)}, \quad c(u)=c\left(u_{0}\right)+\delta\left(u-u_{0}\right) .
$$

Параметры в аппроксимациях (3) подобраны для наилучшего согласования с представленными в [16] данными. Кроме того, было учтено, что согласно литературным данным [19] коэффициент теплопроводности $(\mathrm{Ga}, \mathrm{Mn}) \mathrm{As}$ при комнатной температуре примерно в 1.5 раза меньше, чем для GaAs.

Для учета теплопередачи на краях моделируемой структуры используется граничное условие третьего рода [18]:

$$
k \frac{\partial u}{\partial x}=\beta\left(u-\theta_{0}\right),
$$

описывающее теплообмен с внешней средой, имеющей постоянную температуру $\theta_{0}$.

Начальным условием в нашей задаче является постоянная температура вдоль всей структуры (Ga, $\mathrm{Mn}) \mathrm{As} / \mathrm{GaAs}$, равная комнатной

$$
u(x, 0)=\theta_{0}
$$

Краевая задача математической физики, заданная выражениями (1)-(5), допускает только численное решение. Для решения квазилинейного уравнения вида (1) использовался метод конечных разностей, включающий неявную схему, применяемую с использованием метода прогонки [18]. Выполнялось моделирование задачи на сетке, содержащей 20000 точек в пространственном интервале от 0 до $2000 \mathrm{~nm}$ (с учетом распространения тепла вглубь подложки GaAs) и 2000 точек во временном интервале от 0 до 100 ns. Для процессов, генерируемых импульсом длительностью $30 \mathrm{~ns}$ и протекающих в интересующем нас слое толщиной около $300 \mathrm{~nm}$, в котором расположена последовательность квантовых ям (см. рис. 1), указанный размер сетки представляется 


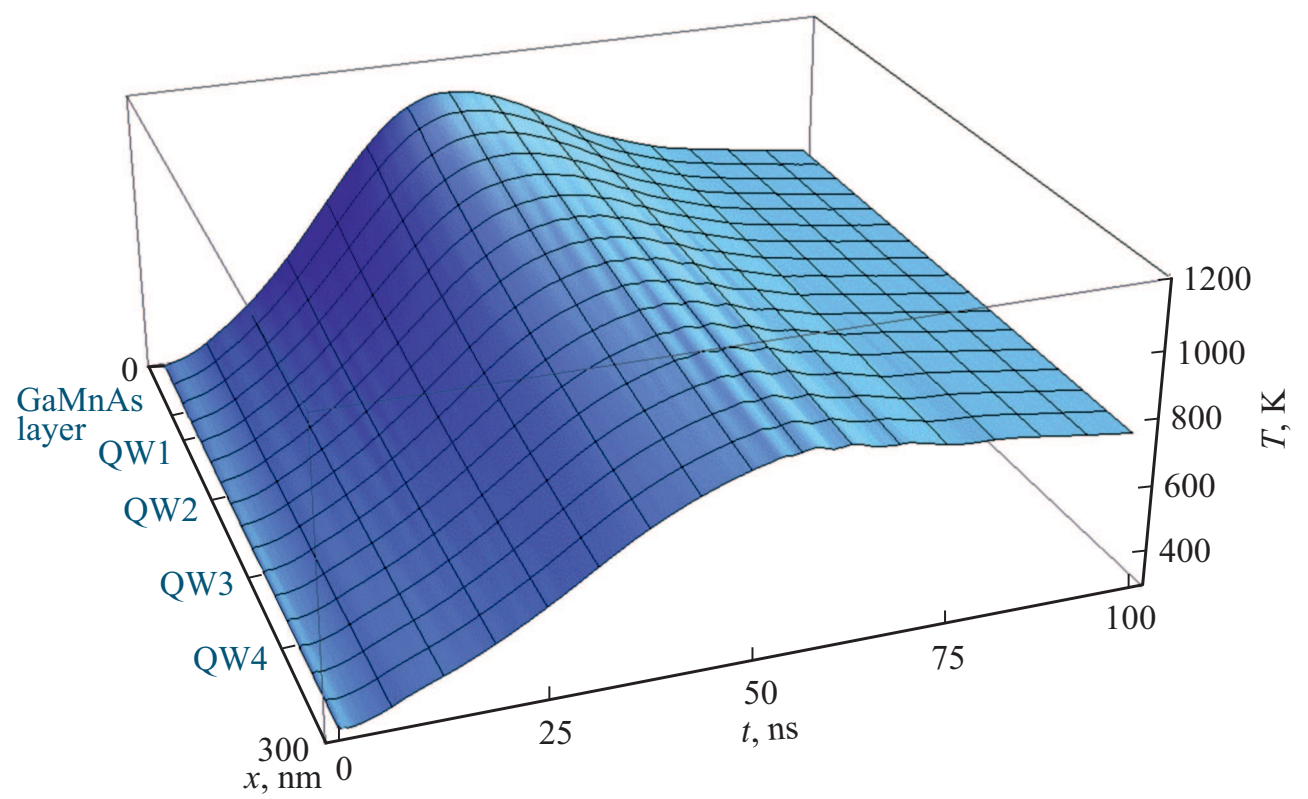

Рис. 4. Рассчитанное распределение температуры вдоль толщины образца и во времени при облучении импульсом с плотностью энергии $300 \mathrm{~mJ} / \mathrm{cm}^{2}$.

оптимальным. Дальнейший рост числа узлов сетки, как показало наше моделирование, существенно не влияет на точность основного результата о прогреве указанной области структуры.

Результаты моделирования показали, что температура плавления GaAs, равная $1515 \mathrm{~K}$, не может быть достигнута в приповерхностном слое $(\mathrm{Ga}, \mathrm{Mn}) \mathrm{As}$ толщиной 40-50 nm при использовании плотности энергии излучения $P$ в диапазоне от 200 до $360 \mathrm{~mJ} / \mathrm{cm}^{2}$. Пример температурного поля с разверткой по толщине образца в пределах области с квантовыми ямами и по времени приведен на рис. 4 для $P=300 \mathrm{~mJ} / \mathrm{cm}^{2}$.

Видно, что максимальная температура достигается в приповерхностном слое вскоре после прохождения максимума лазерного импульса, и постепенно спадает во времени, а также вглубь структуры. После окончания импульса температура на глубине $300 \mathrm{~nm}$ устанавливается в пределах 700-800 К. Максимальная температура, достигаемая на глубинах, соответствующих положению всех четырех квантовых ям GaAs, показана на рис. 5, a и представляет собой монотонно возрастающую величину на зависимости от плотности энергии лазерного импульса.

\section{5. Обсуждение результатов}

Вначале остановимся подробнее на выяснении основных механизмов влияния импульсного лазерного воздействия на излучательные свойства (фотолюминесценцию) гетероструктур с квантовыми ямами и слоем ( $\mathrm{Ga}, \mathrm{Mn}) \mathrm{As}$ на поверхности. В первую очередь отметим уменьшение интенсивности излучения квантовых ям с увеличением плотности энергии лазерного излучения (рис. $5, b)$. Этот эффект наблюдался нами и для случая лазерного воздействия на гетероструктуры с высокотемпературным (HТ - high-temperature) (полученным МОСГЭ) покровным слоем GaAs [12]. Было показано, что для таких структур снижение интенсивности излучения квантовых ям в результате воздействия импульсного лазерного излучения происходит вследствие релаксации напряжений на границе раздела „квантовая яма InGaAs/GaAs барьер“. При релаксации механических напряжений создаются дислокации несоответствия, а на начальных стадиях процесса формирования дислокаций в квантовых ямах появляются точечные дефекты, которые приводят к длинноволновому смещению пиков фотолюминесценции квантовых ям и служат центрами безызлучательной рекомбинации, что вызывает уменьшение интенсивности фотолюминесценции [12].

В случае структур со слоем ( $\mathrm{Ga}, \mathrm{Mn}) \mathrm{As}$, полученным при пониженной температуре методом ИЛН, процесс гашения люминесцентного излучения двух ближайших к поверхности квантовых ям происходит при меньшей плотности энергии лазерного излучения $\left(360 \mathrm{~mJ} / \mathrm{cm}^{2}\right)$ против более $400 \mathrm{~mJ} / \mathrm{cm}^{2}$ для случая структуры с HT-GaAs. Кроме того, существенного влияния плотности энергии на положение пиков ФЛ квантовых ям в спектрах не регистрируется (рис. 1).

Вероятно, основные причины таких особенностей поведения излучательных свойств обусловлены структурным несовершенством слоя ( $\mathrm{Ga}, \mathrm{Mn}) \mathrm{As}$, который может содержать точечные дефекты и избыточный марганец в междоузлиях. Из расчетных зависимостей максимальной температуры в области расположения каждой из четырех квантовых ям при различных плотностях энергии импульса лазерного излучения (рис. 5,a) следует, что 

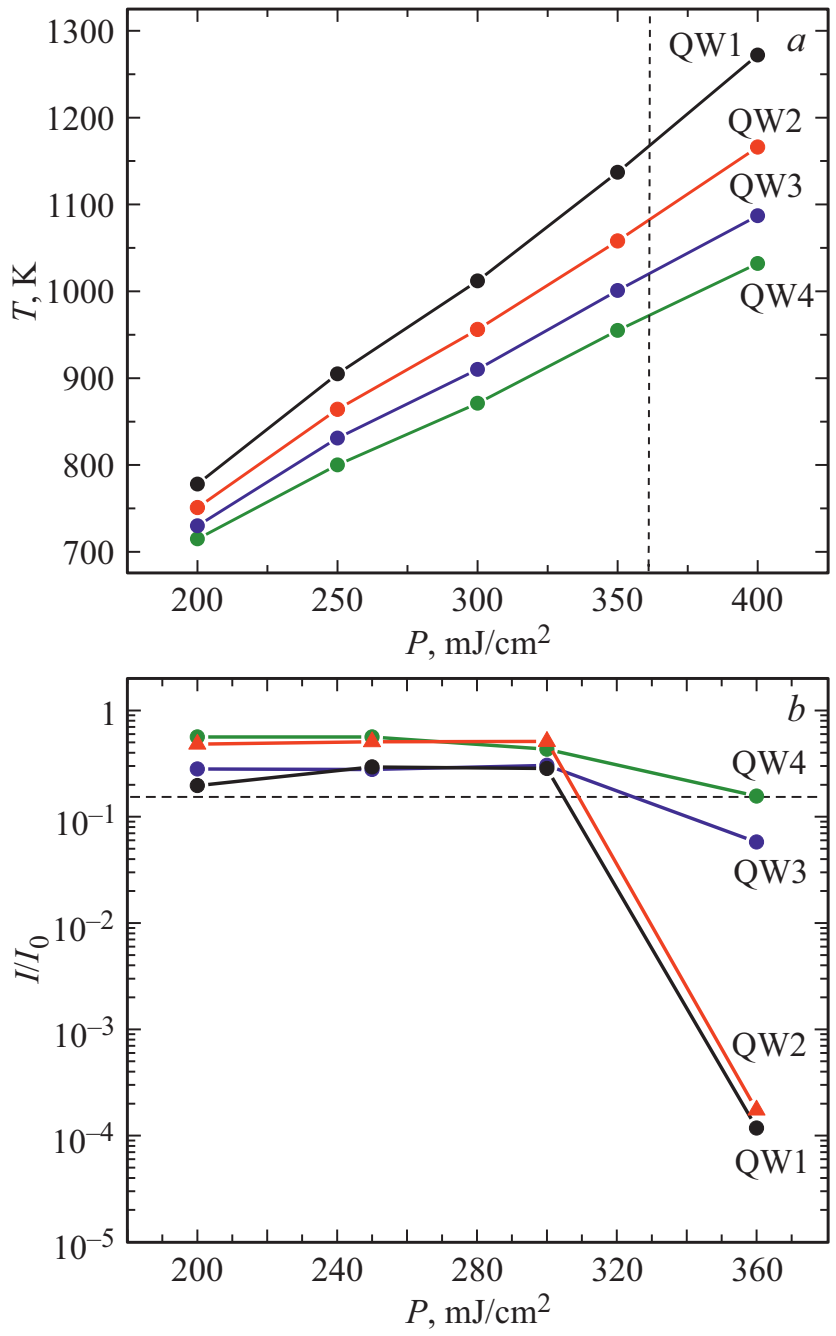

Pис. 5. $a-$ расчетные зависимости максимальной температуры в области расположения каждой из четырех квантовых ям при различных плотностях энергии импульса лазерного излучения; $b-$ экспериментальные зависимости гашения интенсивности фотолюминесценции (отношение интенсивности пика ФЛ к исходному значению $I_{0}$ ) при варьировании плотности энергии для квантовых ям QW1, QW2, расположенных вблизи поверхности структуры, и для квантовых ям QW3, QW4.

в данном случае температура в области квантовых ям в среднем на 80- $100 \mathrm{~K}$ выше, чем для гетероструктур с HT-GaAs слоем на поверхности. Этот факт, с одной стороны, объясняет более „раннее“ (по плотности энергии) гашение сигнала ФЛ квантовых ям, а, с другой стороны, позволяет предположить, что при таких более высоких температурах начинает работать также диффузионное перемешивание на границе раздела „квантовая яма InGaAs/GaAs-барьер“. Вследствие этого гетерограница размывается, квантовая яма становится эффективно мельче, и в спектре может наблюдаться „синий“ сдвиг пиков ФЛ квантовых ям, который компенсирует их возможное длинноволновое смещение, возникающее благодаря релаксации напряжений сжатия нанослоев InGaAs.

Для выяснения роли точечных дефектов в процессе лазерного воздействия были проведены эксперименты по импульсному лазерному отжигу гетероструктур с квантовыми ямами и изготовленным при $T_{g}=400^{\circ} \mathrm{C}$ методом ИЛН низкотемпературным (LT - low-temperature) слоем GaAs (толщиной $\sim 40 \mathrm{~nm}$ ) на поверхности, и осуществлен сравнительный анализ относительного изменения интенсивности ФЛ квантовой ямы, ближайшей к покровному слою, со структурами с HT-GaAs и ( $\mathrm{Ga}, \mathrm{Mn})$ As-слоями. Результаты показаны на рис. 6.

Видно, что для структуры с низкотемпературным покровным слоем GaAs полное гашение сигнала квантовой ямы QW1 наступает при существенно меньшем значении плотности энергии лазерного излучения (немного больше $300 \mathrm{~mJ} / \mathrm{cm}^{2}$ ), чем для структур со слоем (Ga, Mn)As и высокотемпературным слоем GaAs на поверхности. Этот эффект можно объяснить диффузией точечных дефектов из покровного слоя LT-GaAs в область квантовой ямы, что приводит к усилению безызлучательной рекомбинации в области квантовой ямы и диффузионному перемешиванию на гетерогранице $\mathrm{InGaAs} / \mathrm{GaAs}$.

Ранее изучение фотоэлектрических свойств структур с низкотемпературным покровным слоем GaAs, полученным методом импульсного лазерного нанесения, показало наличие в нем EL2-центров с глубиной залегания $0.75 \mathrm{eV}$ [20]. EL2-центром называют глубокий донорный уровень в GaAs, идентифицируемый обычно как комплекс, включающий антиструктурный дефект $\mathrm{As}_{\mathrm{Ga}}[21]$. Исследование влияния изохронных термических отжи-

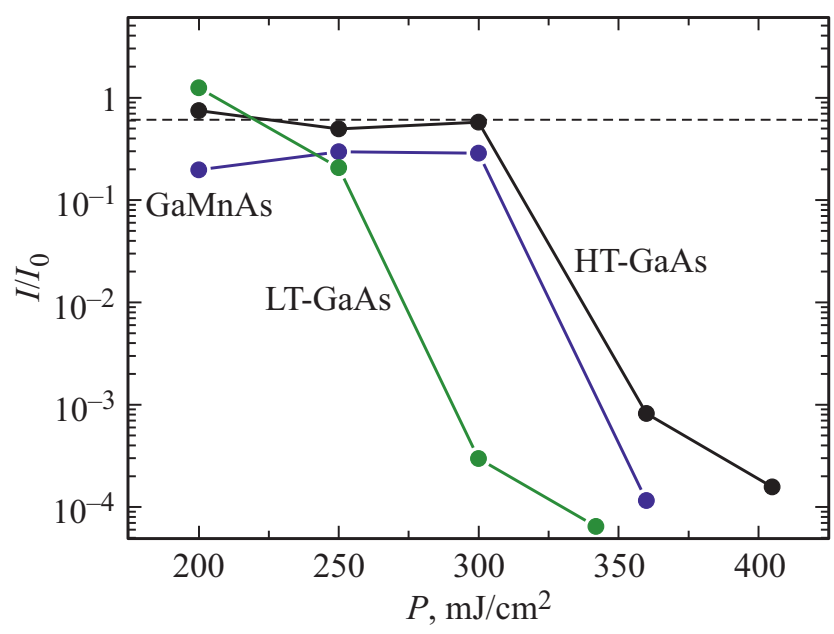

Рис. 6. Зависимости гашения интенсивности фотолюминесценции (отношение интенсивности пика ФЛ к исходному значению $\left.I_{0}\right)$ при варьировании плотности энергии лазерного излучения для ближайшей к поверхности квантовой ямы QW1. Представлены результаты для структур, отличающихся материалом покровного слоя: изготовленный МОСГЭ высокотемпературный арсенид галлия (HT-GaAs), низкотемпературный арсенид галлия (LT-GaAs) и GaMnAs, сформированные ИЛН. 
гов на гетероструктуры с квантовыми ямами и LT-GaAs покровным слоем выявило вызванное диффузией точечных дефектов (в первую очередь вакансий галлия) гашение фотолюминесцентного излучения ближайшей к LT-GaAs-слою квантовой ямы и значительное „синее смещение“ пика ФЛ в спектре при температурах отжига свыше $525^{\circ} \mathrm{C}[22]$. Кроме того, было установлено, что точечные дефекты играют важную роль в диффузии марганца в случае дельта-легированного марганцем низкотемпературного слоя GaAs. Так, изохронный отжиг способствовал диффузии марганца к поверхности и вглубь структуры, причем, в связи с присутствием избыточной концентрации вакансий галлия наблюдалось преимущественное движение атомов Mn в покровный низкотемпературный слой, в результате чего задерживалось проникновение вакансий галлия в область квантовой ямы [22].

Для нашего случая импульсного лазерного отжига структур со слоем (Ga, Mn)As на поверхности кроме изменений в излучательных характеристиках квантовых ям также следует объяснить изменения в электрической активации легирующей примеси. Очевидно, что исходный (необлученный лазером) слой (Ga, Mn)As, выращенный при достаточно низкой температуре $\left(330^{\circ} \mathrm{C}\right)$, может содержать значительное количество вакансий галлия $\left(V_{\mathrm{Ga}}\right)$. Высокая концентрация вакансий галлия $\left(V_{\mathrm{Ga}}\right)$ отмечается, наряду с дефектами $\mathrm{As}_{\mathrm{Ga}}$, в слоях арсенида галлия, выращенных при низких температуpax [23]. При наносекундном лазерном нагреве слоя, с одной стороны, может происходить взаимное диффузионное перемещение на короткие расстояния (несколько нанометров) вакансий галлия и атомов $\mathrm{Mn}$, находящихся первоначально в нерегулярных положениях (например, в междоузлиях, $\left.\mathrm{Mn}_{i}\right)$ в решетке полупроводника. В результате реакции $V_{\mathrm{Ga}}+\mathrm{Mn}_{i}=\mathrm{Mn}_{\mathrm{Ga}}$ увеличивается суммарная электрическая активация атомов марганца в слое $(\mathrm{Ga}, \mathrm{Mn}) \mathrm{As}$, о чем свидетельствуют сравнительные исследования гальваномагнитных свойств исходных и отожженных лазером структур, которые выявили сильное возрастание концентрации носителей заряда (дырок) с увеличением плотности энергии лазерного излучения (до $\sim 6.9 \cdot 10^{20} \mathrm{~cm}^{-3}$ для $P=300 \mathrm{~mJ} / \mathrm{cm}^{2}$ ). Результаты изучения спектров КРС показали усиление вклада фонон-плазмонной моды в спектр комбинационного рассеяния структур. С возрастанием плотности энергии лазерного излучения наблюдалось увеличение интенсивности CPLP-моды и смещение ее в область меньших энергий. Эти результаты хорошо согласуются с литературными данными по изучению положения CPLP-моды в спектре КРС в зависимости от концентрации дырок в слоях ( $\mathrm{Ga}, \mathrm{Mn}) \mathrm{As}$ с различным содержанием марганца, изготовленных методом МЛЭ (рис. 7) [13].

С другой стороны, время повышения температуры в слое $(\mathrm{Ga}, \mathrm{Mn}) \mathrm{As}$ очень коротко, а скорость движения температурного фронта к поверхности при охлаждении образцов настолько велика, что образованием кластеров

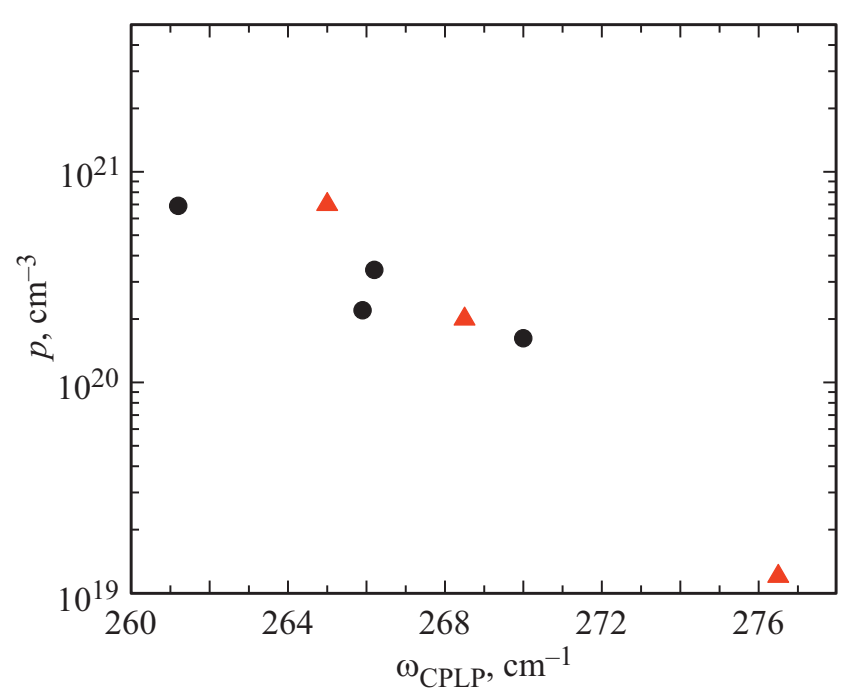

Рис. 7. Концентрации дырок и частотное положение связанной фонон-плазмонной моды для слоя $(\mathrm{Ga}, \mathrm{Mn}) \mathrm{As}$. Экспериментальные данные для исходного и отожженного лазером образцов структуры со слоем ( $\mathrm{Ga}, \mathrm{Mn}) \mathrm{As}$, сформированным методом импульсного лазерного нанесения, показаны кружками. Данные [13] для (Ga, Mn)As с содержанием марганца до 8.3\%, изготовленного методом LT-МЛЭ, представлены символами в виде треугольников.

типа GaMn и/или MnAs и уходом в них атомов марганца можно пренебречь.

Кроме того, участие точечных дефектов исходного слоя в процессе дополнительной активации атомов Мn предотвращает их диффузионное проникновение в квантовые ямы (в отличие от случая низкотемпературного слоя GaAs, не содержащего марганца - см. рис. 6).

Температуру Кюри в ( $\mathrm{Ga}, \mathrm{Mn}) \mathrm{As}$, учитывая тот факт, что она пропорциональна концентрации $\mathrm{Mn}_{\mathrm{Ga}}$ и концентрации электрически-активных дырок $(p)$ [24], чаще всего определяют следующим образом:

$$
T_{C} \sim\left[\mathrm{Mn}_{\mathrm{Ga}}\right] \times p^{1 / 3},
$$

где

$$
p=\left[\mathrm{Mn}_{\mathrm{Ga}}\right]-2\left(\left[\mathrm{As}_{\mathrm{Ga}}\right]+\left[\mathrm{Mn}_{i}\right]\right) .
$$

Поэтому максимальная температура фазового перехода ферромагнетик-парамагнетик достигается при максимальном значении концентрации дырок, акцепторов $\mathrm{Mn}_{\mathrm{Ga}}$ и минимальных концентрациях точечных дефектов донорного типа: антиструктурный дефект мышьяк в положении галлия $\left(\mathrm{As}_{\mathrm{Ga}}\right)$ и марганец в междоузлии $\left(\mathrm{Mn}_{i}\right)$.

В нашем случае в результате применения импульсного лазерного отжига для обработки структур с (Ga, Mn)As-слоем на поверхности было зарегистрировано при гальваномагнитных исследованиях в температурном диапазоне от 10 до $300 \mathrm{~K}$ значительное изменение в поведении магнитополевых зависимостей сопротивления Холла $R_{\mathrm{H}}$. Было установлено, что образец, отожженный лазером с плотностью энергии $300 \mathrm{~mJ} / \mathrm{cm}^{2}$, имеет 


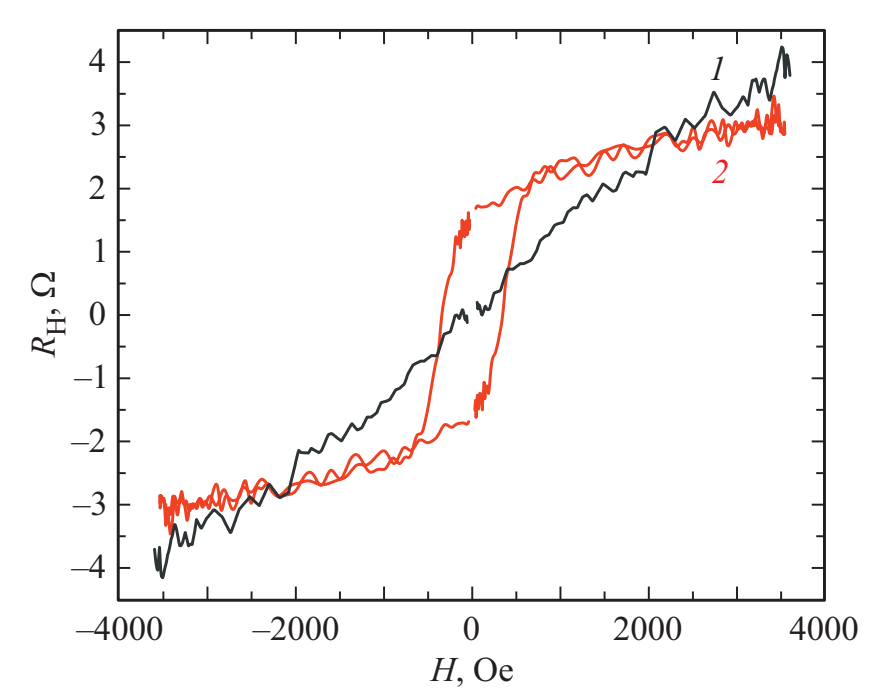

Рис. 8. Магнитополевые зависимости сопротивления Холла для исходного образца при $100 \mathrm{~K}(1)$ и отожженного лазером с плотностью энергии $300 \mathrm{~mJ} / \mathrm{cm}^{2}$ при $120 \mathrm{~K}$ (2).

нелинейную зависимость $R_{\mathrm{H}}(H)$ с петлей гистерезиса вплоть до $120 \mathrm{~K}$ (рис. 8). Исходный образец имел температуру Кюри не более $30-40$ К и при температуре $100 \mathrm{~K}$ демонстрировал линейную зависимость холловского сопротивления от магнитного поля. Наблюдаемое влияние лазерного воздействия на поведение зависимостей $R_{\mathrm{H}}(H)$ свидетельствует о возрастании температуры Кюри для отожженных образцов до значений не ниже $120 \mathrm{~K}$.

\section{6. Заключение}

Таким образом, проведенные исследования показали, что вследствие импульсного лазерного воздействия на квантово-размерные структуры с покровным слоем (Ga, Mn)As при определенном диапазоне плотности энергии лазерного излучения (до $250-300 \mathrm{~mJ} / \mathrm{cm}^{2}$ ) удается сохранить излучательные свойства активной области (квантовой ямы InGaAs/GaAs), расположенной на расстоянии 10-12 nm от слоя ( $\mathrm{Ga}, \mathrm{Mn}) \mathrm{As}$ и модифицировать ферромагнитные свойства полупроводника (Ga, Mn)As, а именно, увеличить температуру фазового перехода ферромагнетик-парамагнетик до значений не менее $120 \mathrm{~K}$. Полученные результаты могут представлять интерес для технологии приборов спиновой оптоэлектроники.

\section{Финансирование работы}

Работа выполнена при поддержке Российского научного фонда (грант No 19-19-00545).

\section{Конфликт интересов}

Авторы заявляют, что у них нет конфликта интересов.

\section{Список литературы}

[1] S. Ghosh, P. Bhattacharya. Appl. Phys. Lett. 80, 658 (2002).

[2] M. Holub, J. Shin, S. Chakrabarti, P. Bhattacharya. Appl. Phys. Lett. 87, 091108 (2005).

[3] P. Van Dorpe, Z. Liu, W. Van Roy, V.F. Motsnyi, M. Sawicki, G. Borghs, J. De Boeck. Appl. Phys. Lett. 84, 3495 (2004).

[4] Y. Ohno, F. Matsukura, H. Ohno. Physica E 32, 438 (2006).

[5] Б.Н. Звонков, О.В. Вихрова, Ю.А. Данилов, Е.С. Демидов, П.Б. Демина, М.В. Дорохин, Ю.Н. Дроздов, В.В. Подольский, М.В. Сапожников. Опт. журн. 75, 56 (2008).

[6] Б.Н. Звонков, О.В. Вихрова, Ю.А. Данилов, Ю.Н. Дроздов, А.В. Кудрин, М.В. Сапожников. ФТТ 52, 2124 (2010).

[7] Е.И. Малышева, М.В. Дорохин, А.В. Здоровейщев, М.В. Ведь. ФТТ 58, 2190 (2016).

[8] О.В. Вихрова, Ю.А. Данилов, Б.Н. Звонков, П.Б. Демина, М.В. Дорохин, И.Л. Калентьева, А.В. Кудрин. ФТТ 59, 2196 (2017).

[9] О.В. Вихрова, Ю.А. Данилов, Б.Н. Звонков, А.В. Здоровейщев, А.В. Кудрин, В.П. Лесников, А.В. Нежданов, С.А. Павлов, А.Е. Парафин, И.Ю. Пашенькин, С.М. Планкина. ФТТ 59, 2130 (2017).

[10] Е.И. Малышева, М.В. Дорохин, Ю.А. Данилов, А.Е. Парафин, М.В. Ведь, А.В. Кудрин, А.В. Здоровейщев. ФТТ 60, 2141 (2018).

[11] D. Nečas, P. Klapetek. Cent. Eur. J. Phys. 10, 181 (2012).

[12] О.В. Вихрова, Ю.А. Данилов, Б.Н. Звонков, И.Л. Калентьева, А.В. Нежданов, А.Е. Парафин, Д.В. Хомицкий, И.Н. Антонов. ФТП 54, 1336 (2020).

[13] W. Limmer, M. Glunk, S. Mascheck, A. Koeder, D. Klarer, W. Schoch, K. Thonke, R. Sauer, A. Waag. Phys. Rev. B 66, 205209 (2002).

[14] M.J. Seong, S.H. Chun, H.M. Cheong, N. Samarth, A. Mascarenhas. Phys. Rev. B 66, 033202 (2002).

[15] В.И. Гавриленко, А.М. Грехов, Д.В. Корбутяк, В.Г. Литовченко. Оптические свойства полупроводников. Наук. думка, Киев (1987). 607 с.

[16] T. Kim, M.R. Pillai, M.J. Aziz, M.A. Scarpulla, O.D. Dubon, K.M. Yu, J.W. Beeman, M.C. Ridgway. J. Appl. Phys. 108, 013508 (2010).

[17] P. Baeri, S.U. Campisano. Laser Annealing in Semiconductors / Ed. J.M. Poate, J.W. Mayer. Academic Press, N.Y. (1982). P. $75-111$.

[18] А.Н. Тихонов, А.А. Самарский. Уравнения математической физики. Наука, М. (1977).

[19] I.V. Soldatov, N. Panarina, C. Hess, L. Schultz, R. Scheafer. Phys. Rev. B 90, 104423 (2014).

[20] А.П. Горшков, И.А. Карпович, Е.Д. Павлова, И.Л. Калентьева. ФТП 46, 194 (2012).

[21] E.R. Weber. Physica B 340-342, 1 (2003).

[22] И.Л. Калентьева, О.В. Вихрова, Ю.А. Данилов, Б.Н. Звонков, А.В. Кудрин, М.Н. Дроздов. ФТП 50, 1490 (2016).

[23] A. Krotkus, J.-L. Coutaz. Semicond. Sci. Technol. 20, S142 (2005).

[24] Y.L. Soo, G. Kioseoglou, S. Kim, X. Chen, H. Luo, Y.H. Kao, Y. Sasaki, X. Liu, J.K. Furdyna. Appl. Phys. Lett. 80, 2654 (2002).

Редактор Ю.Э. Китаев 